\title{
Development of zoophilic interests and behaviors in the example of an adolescent male
}

\author{
Marta E. Szymańska-Pytlińska (1D ${ }^{1 \cdot A, B, D, E, F}$, Maria f. Beisert (D) ${ }^{1 \cdot A, D, E}$, Agnieszka U. Stopień (D) ${ }^{2 \cdot E}$ \\ 1: Faculty of Psychology and Cognitive Science, Adam Mickiewicz University, Poznan, Poland \\ 2: Department of Child and Adolescent Psychiatry, Poznan University of Medical Sciences, Poznan, Poland
}

BACKGROUND

In the research literature the phenomenon of bestiality is considered as a form of animal abuse or as an expression of love and affection toward animals or even as another sexual orientation.

\section{PARTICIPANTS AND PROCEDURE}

The article elucidates the mechanisms of development and maintenance of paraphilia in an 18-year-old single male. Psychological evaluation was conducted with both clinical and psychometric measures. The patient's course of psychosexual development is characterized by two perspectives - his own and that of his mother.

\section{RESULTS}

At the time of the assessment, the subject's primary sexual outlet was masturbation and zoophilic sexual contact with sheep. The deviation developed over ten years prior to the exposure of the patient's zoophilic interests. The diagnostic process indicated that the subject suffers from significant psychopathology. Following the assessment, the patient was diagnosed with another disorder of sexual preference (F65.8) based on the ICD-10 criteria. The mechanisms of development and maintenance of his paraphilia are discussed with regard to other research.

\section{CONCLUSIONS}

Patients who have sex with animals, or who fantasize about doing so, often struggle with negative reactions from their therapists (including a lack of knowledge, laughter, and pressure) when they decide to disclose their experiences. The article may be useful to clinicians who encounter this problem in their practice as an example of the functional capturing of this phenomenon.

\section{KEY WORDS}

diagnosis; zoophilia; bestiality

Corresponding Author - Marta E. Szymańska-Pytlińska, Ph.D., Faculty of Psychology and Cognitive Science, Adam Mickiewicz University, 89/AB Szamarzewskiego Str., 60-568 Poznan, Poland, e-mail: marta.szymanska-pytlinska@amu.edu.pl

AUthors' CONtribution - A: Study design · B: Data collection · C: Statistical analysis · D: Data interpretation ·

E: Manuscript preparation · F: Literature search · G: Funds collection

to Cite this ARticle - Szymańska-Pytlińska, M. E., Beisert, M. J., \& Słopień, A. U. (2021). Development of zoophilic interests and behaviors in the example of an adolescent male. Current Issues in Personality Psychology, 9(1), 26-36. RECEIVED 26.08.2020 • REVIEWED 02.09.2020 • ACCEPTED 06.10.2020 • PUBLISHED 27.11.2020 


\section{BACKGROUND}

Sexual acts with animals are referred to as zoophilia and bestiality. The first term often occurs in the context of clinical diagnosis of sexual preference, while the second describes sexual contact with an animal (Beetz, 2008). Recent research, carried out mostly online, recruits and tests samples consisting of people who have sex with animals (PSA) to capture the problem more broadly (Sendler, 2019). The prevalence of bestiality in the general population is lower than that found in clinical samples and among incarcerated men, especially sexual offenders (Table 1). A few studies have shown that bestiality is less frequently reported by subjects in self-report measures than in polygraph testing (Emerick \& Dutton, 1993; English et al., 2003; Schenk et al., 2014). The scale of the phenomenon is likely to be greater than reported by the studies. Contemporary research presents bestiality either as a form of animal abuse (e.g., Miller \& Knutson, 1997; Simons et al., 2008; Tallichet et al., 2005; Hensley et al., 2006; Hensley et al., 2010) that poses a risk factor for future interpersonal violence, or as an expression of love and affection toward animals (e.g., Miletski, 2002, as cited in Beetz, 2005a; Williams \& Weinberg, 2003). Miletski (2017) goes even further and deliberates whether zoophilia could be considered another sexual orientation.

Taking into account the prevalence described above, it is highly probable that clinicians (psychologists, psychiatrists, and sexologists) will encounter the issue of sex with animals in their practice. The case report delineated in this article aims to show the development of paraphilia in a single male teenager with the aim of presenting new insights to clinicians working with patients who perform sexual

\section{Table 1}

Prevalence of zoophilic fantasies and behaviors in various samples

\begin{tabular}{|c|c|c|c|c|c|}
\hline Study & Sample & $N$ & $\begin{array}{c}\text { Prevalence } \\
\text { rate } \%\end{array}$ & $\begin{array}{l}\text { Type of activity } \\
\text { regarding animals }\end{array}$ & Source \\
\hline \multirow[t]{2}{*}{ Kinsey et al., 1948} & American males & 5300 & $8 \%$ & sexual activity & self-report \\
\hline & & & $1-2 \%$ & $\begin{array}{l}\text { sexual fantasies } \\
\text { about animals }\end{array}$ & \\
\hline \multirow[t]{2}{*}{ Kinsey et al., 1953} & American females & 5800 & $3 \%$ & sexual activity & self-report \\
\hline & & & $0.6-1.3 \%$ & $\begin{array}{l}\text { sexual fantasies } \\
\text { about animals }\end{array}$ & \\
\hline \multirow[t]{2}{*}{ Hunt, 1974} & men & 982 & $5 \%$ & sexual activity & self-report \\
\hline & women & 1044 & $2 \%$ & sexual activity & self-report \\
\hline Abel et al., 1988 & $\begin{array}{c}\text { nonincarcerated } \\
\text { paraphiliacs }\end{array}$ & 561 & $2.5 \%$ & bestiality & self-report \\
\hline \multirow[t]{3}{*}{ Alvarez \& Freinhar, 1991} & $\begin{array}{l}\text { psychiatric } \\
\text { inpatients }\end{array}$ & 20 & $55 \%$ & $\begin{array}{c}\text { sexual activity } \\
\text { or sexual fantasies }\end{array}$ & self-report \\
\hline & medical inpatients & 20 & $10 \%$ & about animals & \\
\hline & $\begin{array}{c}\text { psychiatric staff } \\
\text { members }\end{array}$ & 20 & $15 \%$ & & \\
\hline \multirow[t]{4}{*}{ Miller \& Knutson, 1997} & $\begin{array}{l}\text { incarcerated men } \\
\text { and women }\end{array}$ & 299 & $5 \%$ & $\begin{array}{c}\text { touching an animal } \\
\text { sexually }\end{array}$ & self-report \\
\hline & & & $7 \%$ & $\begin{array}{c}\text { watching someone } \\
\text { have sex with } \\
\text { an animal }\end{array}$ & \\
\hline & & & $3 \%$ & having sex & \\
\hline & $\begin{array}{l}\text { university } \\
\text { students }\end{array}$ & 308 & $2 \%$ & $\begin{array}{l}\text { witnessing or } \\
\text { engaging in sexual } \\
\text { acts with animals }\end{array}$ & \\
\hline
\end{tabular}


Table 1

(Table 1 continued)

\begin{tabular}{lccccc}
\hline Study & Sample & $N$ & $\begin{array}{c}\text { Prevalence } \\
\text { rate } \%\end{array}$ & $\begin{array}{c}\text { Type of activity } \\
\text { regarding animals }\end{array}$ & Source \\
\hline Fleming et al., 2002 & $\begin{array}{c}\text { male juvenile } \\
\text { offenders }\end{array}$ & 381 & $6 \%$ & $\begin{array}{c}\text { something sexual } \\
\text { with an animal }\end{array}$ & self-report \\
Sandnabba et al., 2002 & $\begin{array}{c}\text { sadomasochistic } \\
\text { men }\end{array}$ & 164 & $7.4 \%$ & $\begin{array}{c}\text { sexual activity } \\
\text { during the last } \\
12 \text { months }\end{array}$ & self-report \\
English et al., 2003 & $\begin{array}{c}\text { sexual offenders } \\
\text { (of both sexes) }\end{array}$ & 180 & $36 \%$ & sexual activity & polygraph \\
Simons et al., 2008 & $\begin{array}{c}\text { male child sexual } \\
\text { abusers }\end{array}$ & 132 & $38 \%$ & sexual activity & self-report \\
Schenk et al., 2014 & $\begin{array}{c}\text { male rapists } \\
\text { male juvenile sex } \\
\text { offenders }\end{array}$ & 32 & $37.5 \%$ & sexual activity & self-report \\
Holoyda, 2017 & sexual offenders & 84 & $3.6 \%$ & sexual activity & polygraph \\
\hline
\end{tabular}

behaviors with animals, or who fantasize about doing so. In accordance with the life span theory, the current psychosexual functioning of the subject is described in the context of the former stages of his development. In particular, data on the earlier motor, cognitive, emotional, social, and sexual functioning of the patient are taken into account. Careful analysis of the psychosexual biography of an individual, accompanied by psychological testing and psychiatric diagnosis, gives specific, in-depth information that could be useful in understanding the mechanisms of development and maintenance of zoophilic interests and behaviors. We go beyond nosological diagnosis with the use of the International statistical classification of diseases and related health problems, 10th revision (ICD-10; WHO, 1992).

\section{PARTICIPANTS AND PROCEDURE}

\section{PARTICIPANT}

DF, an 18-year-old single male, was admitted to the Child and Adolescent Psychiatry Clinic because he was caught performing intravaginal contact with a sheep, and afterwards attempted to commit suicide. The patient reported to the hospital voluntarily. He presented depressed mood and declared that he "would like to fight what disgusts him" - namely, his "alternative way of satisfying his sexual needs". At the time of the assessment he was attending vocational secondary school and planned to become an IT specialist. He lived on the outskirts of a city of more than 500,000 residents in Poland.

\section{MEASURES}

Psychological evaluation was conducted during five weeks of hospitalization by the first author. The psychological assessment was designed to provide information about the patient's cognitive, emotional, social, and sexual functioning. The diagnostic process involved both clinical and psychometric measures. The Revised Wechsler Adult Intelligence Scale (WAIS-R; Polish version: Brzeziński et al., 2004) and the Minnesota Multiphasic Personality Inventory 2 (MMPI-2; Polish version: Brzezińska et al., 2012) were administered. We also used the Thematic Apperception Test (TAT; based on Murray, 1943) to gain insight into motive content. We used twenty picture cards during the diagnostic process. They were selected according to the male sex of the subject. Cards were presented in two series (ten cards per session). We asked the subject to tell a story for each picture, including the information what has led up to the shown situation, what is happening in the scene, what the thoughts and feelings of the characters are, and what the outcome of the story could be. The stories were recorded, transcribed and then analyzed according to the SCORS and DMM assessment system (as cited and described by Stemplewska-Żakowicz, 2004). The first and second authors carried out a clinical interview regarding the psychosexual biography of the participant. This took the form of standardized questions regarding the patient's previous phases of sexual development, as well as his current sexual behaviors. Information on the early stages (prenatal and postnatal) of the patient's development were provided by his mother, in the course of a clinical interview car- 
ried out by the first author of the report. We chose diagnostic tools that give clinical, psychometric and projective data, and thus complement one another. Their outcomes are not interpreted solely but presented as an integrated description of emotional and social functioning of the subject.

\section{CASE REPORT}

\section{BACKGROUND INFORMATION}

DF was raised in a one-parent family, by his mother. Their housing and financial situations were difficult (e.g., sometimes they lacked money for food). The patient knows from his mother that his father did not want to have a child, and attempted to force her to procure an abortion. The father's contribution to the care of the boy was limited to paying alimony and (rarely) to babysitting. In childhood, DF experienced physical and psychological violence from both parents.

The patient was a child with a history of medical problems. His mother recalled that DF's natural birth was problematic and involved prolonged labor. The use of forceps was required and, in her opinion, this is what impaired her son's sight. Despite this, delivery had to be completed by cesarean section. The newborn child was assessed with an Apgar score of 6 . DF had reduced muscle tone and responded vaguely to stimulation. The ophthalmologist diagnosed nystagmus and astigmatism. DF had seizures during infancy and was treated with Depakine Chrono (valproate) until the age of 4-5. His mother recalls that seizures began when the boy was 12-18 months old, and estimates their initial frequency as three to four times a week, later lessening.

With regard to the family history of psychiatric illness, the father of the patient was diagnosed with obsessive-compulsive disorder, his maternal grandmother experienced persecutory delusions, and his mother suffered from depression and was hospitalized after attempted suicide, shortly after DF's birth.

\section{PSYCHOSEXUAL DEVELOPMENT OF DF, AS RECOUNTED BY HIS MOTHER}

In the opinion of his mother, DF's psychomotor development proceeded slowly (he began walking later than his peers), but without significant interruptions. She assessed the speech development of her son to be normal (he spoke his first words before his first birthday) and did not recall any disturbances in toilet training, but had difficulties locating this on a timeline.

His formal education started at age 6. At this time, DF was diagnosed with dyslexia and dysgraphia. The boy had difficulties in locating objects in space and with causal reasoning. The patient's mother was de- termined to support his school education, recalling: "I was a mean mother, I was demanding. We exercised a lot. We did homework together. When he was 12 , I reduced the pressure and left more room for him, and I was satisfied with the results".

Interactions with adults, and especially with his mother, dominated the course of his social development. He started to initiate contact with his peers when he started school, but they were a source of distress to him - they laughed at his glasses and his family's financial situation. His mother reacted to this with hostility toward his peers, so DF stopped informing her about them, and started to isolate her.

Regarding DF's emotional development, his mother recalls that from the beginning he had difficulties in showing both positive and negative feelings. Asked about anger, she said that it could be easily confused with aggression. She remembered that, when he was a child, he threw toys or abandoned what he was doing. He was also aggressive toward animals: "All his life he has been surrounded by animals, but he didn't look after them. Instead he tortured them - tied tape around them, scratched them, beat the dog with a big stick".

The mother did not notice any signs of early sexual expression in DF. When asked what a vagina is and where babies come from, she responded evasively or refused to answer. As far as she knew, DF did not engage in sexual interaction with his peers during childhood. During the interview, she presented a tendency to infantilize the boy and to deny his sexuality as a child. She observed his first sexual behavior when he began puberty, hearing him masturbating in the bathroom at age 13. She did not react, believing that this was a normal sexual need. She also recalled a situation when he was 14 and he stole six cigarettes from her purse. He gave them to a classmate in exchange for her allowing him to touch her breasts. The mother reacted to that situation by supporting her son's behavior, telling him: "If you want to squeeze them again, I'll give you more".

Asked about the current situation (the discovery of his zoophilic interests, his attempted suicide, and his hospitalization), DF's mother answered: "He said he had to blow off steam. I'd even be willing to bring him to a hooker. I'd go to the brothel to save him the trouble, to help him out. Maybe that would help him with his feelings. The act itself, not dating I mean, can be sorted out like this". She also mentioned that she and her partner had tried to initiate interactions with DF's female peers online, through dating sites, on his behalf, but that it did not work out.

\section{PSYCHOSEXUAL AUTOBIOGRAPHY}

DF remembers few facts related to the early phases of his sexual development. Sex in his home was a ta- 
boo. In his opinion, his mother was concerned with staking out the limits of intimacy (e.g., he said that he had never seen her naked) and they did not talk about sexuality. In response to his questions about where babies come from, he was told that they are delivered by storks, grow in cabbages, or come out of women's bellies. His mother helped him with all hygienic activities and accompanied him bathing until he was 6-7 years old. At that time, he was diagnosed with phimosis, and the doctor recommended pulling back the foreskin, but the boy did not want to do so. His mother thus helped him with this while bathing. He stated that he had not performed interactive sexual behavior in childhood, but recalled masturbating with a large red plush toy. He indicated that, in that period of time, he paid no attention to the sexuality of people or animals.

In later childhood (8-9 years old), the Internet became his primary source of knowledge about sexuality. He visited websites that included medical information (e.g., related to genital anatomy) and viewed pornography. When this was discovered by his mother, he learned to delete his search history, which allowed him to avoid parental control. Initially, the content of the porn he viewed was heterosexual, and later zoophilic. He did not prefer pornography involving animals at that time. He could not indicate how often he used it. He did not talk about sexuality with his peers, because he soon realized that he knew much more about the subject.

DF did not recall that the onset of puberty affected or altered his interest in human sexuality. He reached biological sexual maturity at the age of 11. Boys of his age began puberty later than him. From the beginning of adolescence, the patient suffered from acute acne, which caused red marks, suppurating lesions, and scars on his face. He felt desperate and embarrassed about it, and his peers bullied him. He liked girls of his age, but was never in a relationship. He attempted to talk to girls, but they responded either with disgust or repulsion. In his opinion, the cause of their negative attitude toward him was his appearance - aside from having acne, he was also overweight. He did not recall sexual interest in males at any age.

DF reported that, in late childhood and early adolescence (8-14 years old), he masturbated approximately once a week, and then more often. Initially, masturbation was accompanied by heterosexual fantasies, which were gradually displaced by images of zoophilic sexual contact. DF sought stronger stimulation and gratification, and began experimenting with various objects. For example, he put his penis into the tube of a vacuum cleaner tube and turned the machine on, but found the cold air unpleasant.

The first sexual interaction with an animal that DF could recall took place in late childhood. When the boy was 8 years old, he experienced oral-genital stimulation performed by the family dog. He could neither describe the circumstances of this situation nor explain why he was naked around the dog's head. He remembered the sexual pleasure caused by the licking and sought to repeat this experience. The boy started to have intercourse with dogs, and later with sheep. He had oral and anal sex with male representatives of these species, and oral and intravaginal sex with females. The patient explained the choice of these animals through two factors: their availability and their anatomical characteristics. He abused dogs living with his family or in the neighborhood, and sheep living in a nearby barn. The animal had to be sufficiently large to have an orifice that allowed penile penetration. Individuals were chosen by their personality. At the beginning, the sex of the animal did not matter to him, but over time he began to prefer intragenital contact over anal sex, so he chose females. Asked about how he decided to approach the animal, he said: "It was an impulse, an instinct, animal lust".

In the period directly preceding the assessment, he performed sexual activity with sheep approximately twice a week, and masturbated once a day, or sometimes less frequently. He believed that he lost control of his sexual behavior at the age of 14-16, as it had become increasingly difficult for him to deal with his sexual drive and to gain distraction from it. He felt the compulsion to undertake sexual activity and this significantly lowered his mood.

The sexual fantasies that DF currently employs during masturbation include both heterosexual and zoophilic images, but the latter impose themselves, and he has to force himself to think about a girl. He fantasizes about vaginal contact with a dog in an impossible sexual position (as he says) - one in which the dog stands calmly on four paws without moving, and he kneels behind her naked, leaning forward with an erection; the animal is immediately wet, so that he can penetrate her vagina and perform the sexual act. When asked how this fantasy differs from reality, DF states that, in order to have sexual intercourse with an animal, one must prepare it (by stimulating its sexual organs with the hand or fingers) and then immobilize it to insert the penis. This process involves tying the animal and forcing it to submit to penetration. Usually, DF copulates with an animal until ejaculation of sperm and orgasm. Afterwards, he feels disgust and grief.

When DF fantasizes about heterosexual contact, he imagines himself with a young woman aged 16-18 years. He is the one who is dominant, who touches the partner, takes the initiative, and performs the act, while she is more passive. They have intravaginal sex in various positions. The boy is able to achieve orgasm during masturbating with this fantasy, but as he says the sexual need returns quickly.

Masturbation is not satisfactory for DF, as the orgasm brings only temporary relief and discharge of 
tension. It was difficult for him to estimate intervals between episodes of autoerotic behavior. He starts masturbating again after one hour or three hours, or sometimes after a few days or weeks. Among the stimulants that excite him, DF lists: racy attire worn by women, large breasts, long legs, and 'alternatives' (the word he sometimes uses to describe sexual contact with an animal). He also recalls that sexual arousal is more likely to appear when he is bored and has too much free time. DF has never experienced sexual contact with another human being, and he has never been in a relationship.

When asked about the current situation (the discovery of his zoophilic interests, his suicide attempt, and his hospitalization), the boy gave limited answers. His zoophilic interests and behaviors were disclosed by a man who took care of the animals with whom DF had coitus. The boy was caught having intercourse with a pregnant sheep, which miscarried in consequence. He was not apprehended, as his mother bribed the animal caregiver. Being caught was the direct cause of attempted suicide. DF declares that, despite the pharmacological treatment, he feels elevated sexual tension, has frequent erections, and feels a need to masturbate every 5-6 hours.

\section{ASSESSMENT OUTCOMES}

The overall level of cognitive function of DF ranged from below average to average (IQ: 86-99). DF's verbal and nonverbal results showed significant discrepancies (IQ Verbal: 101-115, IQ Executive: 63-82), indicating imbalanced development of various intellectual functions. His greatest asset was the storage of verbal material in auditory memory and its reproduction. Substantial deficits appeared in his abilities to perceive part-whole relationships and to differentiate relevant and irrelevant details in presented perceptual material.

The clinical interview, along with MMPI-2 outcomes (he obtained a $\mathrm{T}$ score of above 64 in five clinical scales), indicates that the subject suffers from significant psychopathology. DF presents asocial attitudes and behaviors, reveals feelings of alienation, isolation and separation, and feels uncertain and unhappy in life. He thinks that people do not understand him. DF exhibits poor social skills and avoids deep relationships with other people. $\mathrm{He}$ is introverted and feels intimidated and constrained among people. He expresses his dislike of group activity and uncertainty in new situations, which he thus tends to avoid. His answers suggest that he is more nervous and sensitive than other people, and that he may seek risky and exciting activities to improve his mood. The boy is dysphoric and unhappy with his life situation, and lacks self-confidence. DF reports that he does not have the strength to deal with everyday problems and tension. He experiences anxiety and apathy. $\mathrm{He}$ has the feeling that life is a burden, and sometimes he wants to stop living. His reaction to stress is based on excessive worrying and withdrawal into dreams and fantasies.

DF craves support and rescue, as well as rest. Although declaratively interpersonal relationships are interesting to him, he feels the need for dependence and closeness to others. The way he perceives and describes other people is simple, one-dimensional, and egocentric. The defense mechanisms he uses are immature and based primarily on projection and denial. When confronted with aggressive themes during the interview, he experienced visible difficulties in dealing with the internal conflicts that were raised (suggesting a weakness of the ego). He lost cognitive control over his verbalizations, which could be observed in the disorganization of the process of constructing a narrative.

\section{NOSOLOGICAL AND FUNCTIONAL PSYCHO-SEXUAL DIAGNOSIS}

Following the assessment, we diagnosed DF with another disorder of sexual preference (F65.8) based on the ICD-10 criteria (WHO, 1992) ${ }^{1}$. The boy experiences a repeated intense drive toward sexual activity with animals. This provides him with sexual pleasure and (besides masturbation) it is the only way he achieves sexual satisfaction with another subject. DF's zoophilic behaviors are persistent, frequent (at the time preceding the diagnosis, they occurred approximately twice a week), and compulsive. They emerged early in the course of development (at school age). On the one hand, DF declares that he feels disgusted after zoophilic sexual contact, which suggests that the deviation is egodystonic. On the other hand, he strives to repeat the sexual acts with animals, as they give him orgasms and help to relieve the tension. He suffers as a result of people in his close social environment finding out about his paraphilic interests. DF's masturbation has two intertwined objects - animal and human. However, there is a significant difference between them. The first is dominant and fulfilled in reality, while the other is not.

DF's zoophilia is a result of both constitutional factors and social experiences from the early stages of his psychosexual development. Deviant behaviors appeared, were consolidated, and were maintained via conditioning and social learning mechanisms (Laws \& Marshall, 1990). At the age of 8, having no previous sexual experience, DF had a superficial and incomplete knowledge of sexuality. His sexual initiation was atypical - spontaneously initiated by a dog that licked his genitalia. The direct tactile stimulation of his penis (unconditional stimulus) induced a sexual arousal and erection (an unconditional reac- 
tion). During this experience, the boy could touch the animal, look at it, and smell it. These features were remembered and began to form a pattern of sexual arousal. The pattern started to consolidate, because DF found this event gratifying and strived to repeat the pleasure. On subsequent occasions, the mere presence of the animal, its sight, or its smell may have brought up the memory of oral-genital contact, which in the child's experience was pleasant. The characteristics of this contact and the object itself (animal) served as conditional stimuli, and may have elicited sexual arousal of lesser or greater intensity (a conditional response). An unconventional pattern of sexual reaction, triggered by a specific stimulus, created an opportunity for the development of the pattern of deviant sexual behavior (Laws \& Marshall, 1990). Wishing to recreate the feeling of pleasure resulting from the penile stimulation, DF began to experiment with objects. His sexual experiences broadened to include masturbation accompanied by sexual fantasies about contact with the animal. The chain of associations between the conditional stimulus and the sexual response was strengthened. The conditions for the deviation to develop were facilitated by the constant access of a sexual object (the dog was a family pet) capable of delivering sexual gratification. It was probably not easy for the boy to encourage the animal to spontaneously initiate contact again, so DF modified his modus operandi and deployed other forms of zoophilic sexual activity: anal-genital and genital-genital. The deviancy developed and was irregularly followed by orgasms (reinforcing stimulus) (Laws \& Marshall, 1990). When the dog died and the accessibility of the sexual object was thus decreased, DF began to look for another animals - at first dogs living in the neighborhood. Over time, the boy learned to differentiate potential sexual objects. DF chose dogs and sheep as animals whose anatomy enabled penile penetration, and learned to recognize the temperament of the particular animal in the pack, choosing individuals that he perceived as less aggressive and more submissive.

According to conditioning theory, punishment as a consequence of a behavior can reduce its occurrence (Laws \& Marshall, 1990). Unfortunately, we did not identify either significant environmental or subjective factors that could have stopped the development of the deviancy in the case of DF. The disclosure of his paraphilia took place ten years after the first behavior. The boy did not have any social support other than his mother, who worked a lot as a single parent and was also chronically ill, and therefore often unavailable to the child. The inconsistent manner of the maternal care itself facilitated the development of the deviancy. On one hand, she was negligent of the boy's needs. On the other hand, when she tried to fulfill her son's needs, she acted in an improper way. Her overprotective, demanding, controlling, and infantilizing attitude toward her son impeded the boy's independence and autonomy, strengthening his dependence and passivity. In the process of socialization, the boy adopted social norms that reinforced sociopathic behavior patterns. For example, he learned that it is acceptable to steal cigarettes and to trade them for a chance to touch a friend's breasts. When he was caught by his mother, she supported his action and assured him that she would give him more of her cigarettes for the same purpose. DF's individual traits - such as social introversion, belief in his social and physical unattractiveness, weak social competencies, his interest in computers, and his online activity - all reinforced his social alienation and caused him to become distanced from the peer group which should have been a source of potential sexual partners and social support.

The development of zoophilic behaviors was also facilitated by biological factors. On one hand, the increase in the frequency of sexual behavior (both zoophilia and masturbation to deviant and nondeviant sexual fantasies) undertaken by DF in the 5-7 years preceding diagnosis was associated with normative physiological changes in adolescence (such as increased testosterone levels and increased sexual function) (Bancroft, 2011). On the other hand, the WAIS-R results and his mother's information about the onset of epilepsy in the boy's childhood suggest the presence of neurological deficits. DF declared that, when he undertakes sexual behaviors, he feels compulsion and a sense of losing control. If in this case there is brain damage present in the frontal lobe area, it may be the cause of depressive symptoms, lability, and aggressiveness, weakening DF's critical faculties and affecting his insight. Confirmation of this hypothesis would require a specialist neuropsychological diagnosis.

\section{PSYCHIATRIC DIAGNOSIS AND PHARMACOLOGY}

The subject was admitted to the hospital after a suicide attempt that occurred because he was caught during the sexual contact with a sheep. DF underwent thorough medical examination, interview, blood (blood count, TSH, AlAT, AspAT, bilirubin, creatinine, urea, N, K, glucose) and urine tests, EEG and head CT. The laboratory test showed no abnormalities. EEG and CT outcomes were within the normal range. The subject was given the psychiatric diagnosis of depressive disorder and was treated pharmacologically with paroxetine. Paroxetine is one of the selective serotonin reuptake inhibitors (SSRIs), commonly used in the treatment of depression and anxiety. However, they are also effective in the treatment of paraphilia (Kraus et al., 2006), although little is known about the mechanisms of their action in this group of patients. It is believed that it might be 
a result of anxiety and tension reduction, which leads to lowering intrusion of sexual thought and fantasies regarding paraphilia. This explanation is based on the hypothesis of similarity between paraphilia and symptoms of obsessive-compulsive disorders. During therapy with the SSRI drugs, an increased ability to control unwanted impulses is observed, as well as a reduction in the number of intrusive rumination and fantasies about the sexual act (Gałecki et al., 2010).

\section{COURSE OF TREATMENT}

In the course of the inpatient treatment, DF obtained multifaceted help. He participated in a diagnostic process performed by a psychologist (first author) and a sexologist (second author) and obtained medical treatment from a psychiatrist (third author). He was discharged in a stable mood, with the recommendation to refrain from zoophilic behavior, to continue taking paroxetine, and to begin long-term psychotherapy with a sexologist. Two weeks after discharge, DF participated in a follow-up meeting with a sexologist (the second author) aimed at maintaining his motivation to start therapy and to take pills regularly. The boy began weekly psychotherapeutic sessions and, due to his family's difficult financial situation, obtained social support from a municipal family support center to refund the treatment.

After leaving the hospital ward, a male psychologist-sexologist started working with the patient. The subject was offered integrated therapy, planned as a medium-term therapy, for about 2 years. A contract with the subject included the requirement of abstinence from sexual acts with animals. In the first step, the therapist built a therapeutic relationship with the patient. To do so he was using information about the patient's emotional and social functioning as well as early childhood traumas and early development contained in the written diagnosis provided by the patient. In the second step, the therapist introduced cognitive-behavioral elements focused on changing beliefs about one's own sexuality and fixed habits, adjusting them to the patient's cognitive resources. The introduced themes of cognitive therapy were accompanied by psychoeducation. The therapeutic contact lasted 6 months, with sessions held once a week. However, DF suddenly abandoned the therapy.

\section{DISCUSSION}

The sexual acts with animals undertaken by DF fulfill the criteria of other disorders of sexual preference (F65.8) in the ICD-10 (WHO, 1992). Nevertheless, in terms of the classification proposed by Aggrawal (2011), DF would be recognized as an opportunistic zoosexual, who shows no emotional affection toward animals but has sex with them because they are available, unlike a consenting human being. Earls and Lalumière (2009) suggest that zoophilia can be considered a preference if the subject chooses sexual interaction with an animal when sex with a human is also available. DF has never experienced any form of sexual initiation with a human, but states that he is willing to.

In line with the studies of Gebhard et al. (1965) and Kinsey et al. (1948), DF reported that sex with sheep and dogs was for him a substitute for sex with humans. More current research, conducted online, shows that this motivation is rare among participants. Subjects more frequently state that they prefer sexual contact with animals to that with humans (Miletski, 2002, 2005, as cited in Beetz, 2005a; Williams \& Weinberg, 2003; Beetz, 2004). Research shows that the majority of zoophilic men and women choose canines as sexual objects (Miletski, 2001, 2006; Beetz, 2002, as cited in Beetz, 2005a; Williams \& Weinberg, 2003). DF carried out his sexual behavior with both dogs and sheep. The sexual pleasure and behaviors that he undertook were egodystonic, and he declared that he wanted to stop having sex with animals. By contrast, the vast majority of respondents in the study of Miletski (2001) - 92\% of 93 participants of both sexes - did not want to change their sexual behavior, as they enjoyed both the sex and the relationship with the animal partners. Similar results were found by, for example, Williams and Weinberg (2003). Nevertheless, we assessed DF's motivation to change the pattern of sexual behaviors to be weak. We perceived his declarations to be concordant with what is socially approved, but his vision of sexual life with humans was rather ungratifying and full of anxiety regarding social interactions. An attempted suicide, as DF did, also occurred among $23 \%$ of zoophiles examined by Miletski (2002, 2005b, as cited in Miletski, 2006), and by about $8 \%$ (1 in 12) of bestialic, sadomasochistically oriented individuals in a study carried out by Sandnabba et al. (2002).

DF has been socialized to satisfy his needs of intimacy and sexuality through maladaptive means. He reported a developmental history characterized by parental violence and neglect and maladaptive behaviors. As his mother recalled, DF engaged in cruelty toward animals during childhood. Beetz (2005a) argues that a link between bestiality and violence is not as obvious as the literature suggests (e.g., Miller \& Knutson, 1997; Simons et al., 2008; Tallichet et al., 2005; Hensley et al., 2006; Hensley et al., 2010). She mainly points out that such a link tends to be reported in research carried out in special nonrepresentative populations - most often among criminals (Beetz, 2005a). Nevertheless, it seems that in the case of DF there is an association between being an object of parental physical abuse and neglect and becoming 
physically and sexually abusive to animals. As the abused-abuser hypothesis proposes: he switched position from being a victim to becoming a perpetrator (Beisert, 2010).

Some of the differences identified between our case report and trends in the research mentioned above might be explained by the young age of DF. The respondents in more contemporary research are usually older than our subject. For example, the mean age of men $(N=113)$ examined by Beetz (2002, as cited in Beetz 2005a) was 30, and in the research of Miletski $(2002,2005 \mathrm{~b}$, as cited in Miletski, 2006), the men $(n=82)$ were 38 and the women $(n=11)$ were 36 years old on average. Previous case study reports have described, for example, 28- (Amoo et al., 2012), 34- (Bhatia et al., 2005), and 47- (Earls \& Lalumiere, 2009) year-old men. DF experienced his first oral-genital stimulation from a dog very early - in late childhood, at age of 8 . Almost half of respondents in the research of Williams and Weinberg (2003) had their first zoophilic sexual activity later, in adolescence, between 11 and 14 years of age. The average age of onset of zoophilic behaviors in the study of Miletski (2002, as cited in Beetz 2005a) was 13. Two-thirds of men examined by Beetz (2002, as cited in Beetz 2005a) had their first sexual contact with animals before they turned 17, around $50 \%$ had it between 12 and 15 years of age, and only $6 \%$ had it under the age of 10 (like DF).

In the case of DF, the early onset of paraphilic behavior was not accompanied by its exposure, which happened ten years later. During the diagnosis the subject verbalized disgust and grief, but considering the frequency of his zoophilic behavior and the reinforcing characteristics of the orgasms he experiences, since the beginning of the therapeutic process we assessed his motivation for treatment as weak. Miletski (2001) argues that, at first, most zoophiles feel shame and guilt as a result of their sexual interests, but this changes over time. This would suggest that in the case of DF too, the paraphilia may have become egosyntonic and more resistant to psychotherapeutic influences. These conditions all together indicate a heightened risk of further sexual animal abuse by DF.

Future research should investigate the concomitance of bestiality and mental disorders more thoroughly. Bhatia et al. (2005), in their case study of 34-year-old men, identified schizophrenia as a factor that exacerbates bestial behaviors. Amoo et al. (2012) connected the sexual activity with animals undertaken by a 34-year-old man with episodes of depression. DF presented depressive symptoms which (along with the stress caused by the exposure of his paraphilia) led him to attempt suicide, but in his case, the sexual abuse of animals seems to be connected mainly with sexual disinhibition and compulsiveness, and not with depressive mood.

\section{CONCLUSIONS}

This case study has focused on the mechanisms of development and maintenance of zoophilic sexual behaviors in single teenage male; thus it may be useful to clinicians who encounter this problem in their practice. Patients who have sex with animals, or who fantasize about doing so, often struggle with negative reactions from their therapists, when they decide to disclose their experiences (Miletski, 2006). This case report gives clinicians a guide of how to conduct the process of diagnosis and how to integrate gathered data. Using ICD-10 criteria helps to recognize the patient's sexual preferences as healthy or pathological, but it is insufficient to describe the individual pattern of sexual interests that could be addressed during the process of treatment (ZielonaJenek, 2018). To clinically assess the pattern of sexual preferences of a diagnosed patient, we recommend asking further than about the unusualness of the object that is sexually arousing, the behaviors undertaken in the response to the atypical stimuli, its persistence, impact on the patient's functioning and experienced distress. We need to also find out if a patient is able to become sexually aroused in response to more socially and legally acceptable incentives (cf. Zielona-Jenek, 2018). Does the sexual response occur also with non-animal sexual fantasies? Does the subject have sexual experiences with human beings? What is his developmental course, and how can it be used to explain why the pathological pattern has developed? Was sexual contact with an animal the first sexual experience? The latest multinational research by Sendler (2019) reports that $67 \%$ of 345 PSA subjects lost their virginity to an animal, most of them (58\%) to a dog, as in our case report. Psychosexological assessment should go further than concerning sexuality - we assess personality structure, defense mechanisms and abilities to attach to other people and create emotional bonds with them. We also want to assess past traumas and their impact on development and maintenance of a pathological pattern of sexual expression. The question whether zoophilic interests and behaviors are ego-syntonic or ego-dystonic is also important for the prognosis of therapeutic success and relapse prevention (Singg, 2017). Carrying out the diagnosis of cognitive functions is useful to plan therapeutic interventions and strategies. They should always be adjusted to the intellectual abilities of the diagnosed person. Zoophilic interests and behaviors are commonly comorbid with depressive, anxiety and obsessive-compulsive symptoms or suicide attempts (Miletski, 2001; Beetz, 2005b). Lesandrić et al. (2017) suggest that zoophilia might be an early sign of the psychotic process. Thus, psychiatric diagnosis and pharmacological treatment accompanying psycho-sexological therapy are often needed. 


\section{COMPLIANCE WITH ETHICAL STANDARDS}

All procedures involved in the process of diagnosis reported in this case study were carried out in accordance with the ethical standards of the institutional and national research committees, and with the 1964 Helsinki Declaration and its later amendments or comparable ethical standards. Written, informed consent was obtained from the case report subject.

\section{ENDNOTE}

1 The corresponding DSM-5 (APA, 2013) diagnosis would be: other specified paraphilic disorder (zoophilia).

\section{REFERENCES}

Abel, G. G., Becker, J. V., Cunningham-Rathner, J., Mittelman, M., \& Rouleau, J. L. (1988). Multiple paraphilic diagnoses among sex offenders. The Bulletin of the American Academy of Psychiatry and the Law, 16, 153-168. https://doi.org/10.1186/1479-5868-5-12

Aggrawal, A. (2011). A new classification of zoophilia. Journal of Forensic and Legal Medicine, 18, 73-78. https://doi.org/10.1016/j.jflm.2011.01.004

Alvarez, W. A., \& Freinhar, J. P. (1991). A prevalence study of bestiality (zoophilia) in psychiatric in-patients, medical in-patients, and psychiatric staff. International Journal of Psychosomatics, 38, 45-47.

Amoo, G., Abayomio, O., \& Olashore, A. A. (2012). Scientific letter: Zoophilic recidivism in schizophrenia: a case report. African Journal of Psychiatry, 15, 223-225. https://doi.org/10.4314/ajpsy.v15i4.28

APA (2013). Diagnostic and statistical manual of mental disorders (DSM-5). APA Publishing.

Bancroft, J. (2011). Seksualność człowieka [Human sexuality and its problems]. Elsevier Urban \& Partner.

Beetz, A. M. (2004). Bestiality/zoophilia: a scarcely investigated phenomenon between crime, paraphilia, and love. Journal of Forensic Psychology Practice, 4, 1-36. https://doi.org/10.1300/J158v04n02_01

Beetz, A. M. (2005a). Bestiality and zoophilia: Associations with violence and sex offending. In A. L. Podberscek \& A. M. Beetz (Eds.). Bestiality and zoophilia: Sexual relations with animals (pp. 46-70). Purdue University Press.

Beetz, A. M. (2005b). New insights into bestiality and zoophilia. Anthrozoos - Journal of the International Society for Anthrozoology, 18, 98-119.

Beetz, A. M. (2008). Bestiality and zoophilia: a discussion of sexual contact with animals. In F. R. Ascione (Ed.), The international handbook of animal abuse and cruelty: Theory, research, and application (pp. 201-220). Purdue University Press.
Beisert, M. (2010). The importance of the abused-abuser hypothesis in explaining the aetiology of paedophilia. Problems of Forensic Sciences, 81, 57-73.

Bhatia, M. S., Srivastava, S., \& Sharma, S. (2005). An uncommon case of zoophilia. Medicine, Science and the Law, 45, 174-175. https://doi.org/10. 1258\%2Frsmmsl.45.2.174

Brzezińska, U., Koć-Januchta, M., \& Stańczak, J. (2012). MMPI-2 (Minnesocki Wielowymiarowy Inwentarz Osobowości - 2). Podręcznik stosowania, oceny $i$ interpretacji. Wersja Zrewidowana [Minnesota Multiphasic Personality Inventory - 2. Manual]. Pracownia Testów Psychologicznych Polskiego Towarzystwa Psychologicznego.

Brzeziński, J., Gaul, M., Hornowska, E., Machowski, A., \& Zakrzewska, M. (2004). Skala Inteligencji D. Wechslera dla Dorostych. Wersja zrewidowana renormalizacja. WAIS-R (PL). Podręcznik [Wechsler Adult Intelligence Scale - Revised. Manual]. Pracownia Testów Psychologicznych Polskiego Towarzystwa Psychologicznego.

Earls, C. M., \& Lalumiere, M. L. (2009). A case study of preferential bestiality. Archives of Sexual Behavior, 38, 605-609. https://doi.org/10.1177\%2F10790 6320201400106

Emerick, R. L., \& Dutton, W. A. (1993). The effect of polygraphy on the self-report of adolescent sex offenders: Implications for risk assessment. Annals of Sex Research, 6, 83-103. https://doi.org/10.1007/ BF00849301

English, K., Jones, L., Patrick, D., \& Pasini-Hill, D. (2003). Sexual offender containment. Annals of the New York Academy of Sciences, 989, 411-427. https:// doi.org/10.1111/j.1749-6632.2003.tb07322.x

Fleming, W. M., Jory, B., \& Burton, D. L. (2002). Characteristics of juvenile offenders admitting to sexual activity with nonhuman animals. Society and Animals, 10, 31-45. https://doi.org/10.1163/156853 002760030860

Gałecki, P., Talarowska, M., Florkowski, A., Mossakowska, J., \& Depko, A. (2010). Problemy kliniczne w terapii zaburzeń preferencji seksualnych - część druga [Clinical issues in the therapy of the sexual preferences disorders - part two]. Current Problems of Psychiatry, 11, 187-192.

Gebhard, P. H., Gagnon, J. H., Pomeroy, W. B., \& Christenson, C. V. (1965). Sex offenders: Ananalysis of types. Harper Row.

Hensley, C., Tallichet, S. E., \& Dutkiewicz, E. L. (2010). Childhood bestiality: a potential precursor to adult interpersonal violence. Journal of Interpersonal Violence, 25, 557-567. https://doi.org/ $10.1177 \% 2 \mathrm{~F} 0886260509360988$

Hensley, C., Tallichet, S. E., \& Singer, S. D. (2006). Exploring the possible link between childhood and adolescent bestiality and interpersonal violence. Journal of Interpersonal Violence, 21, 910-923. https://doi.org/10.1177\%2F0886260506288937 
Holoyda, B. (2017). Bestiality in forensically committed sexual offenders: a case series. Journal of Forensic Sciences, 62, 541-544. https://doi.org/10.1111/15564029.13255

Hunt, M. (1974). Sexual behavior in the 1970s. Playboy Press.

Kinsey, A. C., Pomeroy, W. B., \& Martin, C. E. (1948). Sexual Behavior in the Human Male. Saunders.

Kinsey, A. C., Pomeroy, W. B., Martin, C. E., \& Gebhart, P. H. (1953). Sexual behavior in the human female. Saunders.

Kraus, C., Strohm, K., Hill, A., Habermann, N., Berner, W., \& Briken, P. (2006). Selective serotonine reuptake inhibitors (SSRI) in the treatment of paraphilia. Fortschritte der Neurologie-psychiatrie, 75, 351-356. https://doi.org/10.1055/s-2006-944261

Laws, D. R., \& Marshall, W. L. (1990). A conditioning theory of the etiology and maintenance of deviant sexual preference and behavior. In W. L. Marshall, D. R. Laws, \& H. E. Barbaree (Eds.) Handbook of sexual assault: Issues, theories, and treatment of the offender (pp. 209-229). Springer.

Lesandrić, V., Orlović, I., Peitl, V., \& Karlović, D. (2017). Zoophilia as an early sign of psychosis. Alcoholism and Psychiatry Research, 53, 27-32. https://doi. org/10.20471/apr.2017.53.01.03

Miletski, H. (2001). Zoophilia - implications for therapy. Journal of Sex Education and Therapy, 26, 85-89. https://doi.org/10.1080/01614576.2001.11074387

Miletski, H. (2006). Introduction to bestiality and zoophilia. Contemporary Sexuality, 40, 8-13.

Miletski, H. (2017). Zoophilia: Another sexual orientation? Archives of Sexual Behavior, 46, 39-42. https://doi.org/10.1007/s10508-016-0891-3

Miller, K. S., \& Knutson, J. F. (1997). Reports of severe physical punishment and exposure to animal cruelty by inmates convicted of felonies and by university students. Child Abuse \& Neglect, 21, 59-82. https://doi.org/10.1016/S0145-2134(96)00131-7

Murray, H. A. (1943). Thematic apperception test. Harvard University Press.

Sandnabba, N. K., Santtila, P., Nordling, N., Beetz, A. M., \& Alison, L. (2002). Characteristics of a sample of sadomasochistically-oriented males with recent experience of sexual contact with animals. Deviant Behavior, 23, 511-529. https://doi. org/10.1080/01639620290086503

Schenk, A. M., Cooper-Lehki, C., Keelan, C. M., \& Fremouw, W. J. (2014). Underreporting of bestiality among juvenile sex offenders: Polygraph versus self-report. Journal of Forensic Sciences, 59, 540-542. https://doi.org/10.1111/1556-4029.12332

Sendler, D. J. (2019). Contemporary understanding of zoophilia - a multinational survey study. Journal of Forensic and Legal Medicine, 62, 44-51. https:// doi.org/10.1016/j.jflm.2018.12.010

Simons, D. A., Wurtele, S. K., \& Durham, R. L. (2008). Developmental experiences of child sexual abus- ers and rapists. Child Abuse \& Neglect, 32, 549560. https://doi.org/10.1016/j.chiabu.2007.03.027

Singg, S. (2017). Ego-dystonic zoophilia: a case report with treatment plan and a critical look at the current state. Clinical Case Reports and Reviews, 3, 1-6. https://doi.org/10.15761/CCRR.1000295

Stemplewska-Żakowicz, K. (2004). O rzeczach widywanych na obrazkach i opowiadanych o nich historiach. TAT jako metoda badawcza i diagnostyczna [Things seen in pictures and stories told about them. TAT as a research and diagnostic method]. SWPS.

Tallichet, S. E., Hensley, C., \& Singer, S. D. (2005). Unraveling the methods of childhood and adolescent cruelty to nonhuman animals. Society \& Animals, 13, 91-108. https://doi.org/10.1163/1568530054300172

Williams, C. J., \& Weinberg, M. S. (2003). Zoophilia in men: a study of sexual interest in animals. Archives of Sexual Behavior, 32, 523-535. https://doi. org/10.1023/A:1026085410617

WHO (1992). International statistical classification of diseases and health related problems, 10th revision. World Health Organization.

Zielona-Jenek, M. (2018). Sexual preferences and associated disorders: Toward an extended model for description. Polish Psychiatry, 52, 1063-1073. https://doi.org/10.12740/PP/82193 